\title{
Instructietechnologie en innovatie van probleemoplossen : over constructiegericht academisch onderwijs
}

Citation for published version (APA):

Dochy, F. (1998). Instructietechnologie en innovatie van probleemoplossen : over constructiegericht academisch onderwijs. Lemma. https://doi.org/10.26481/spe.19981217fd

Document status and date:

Published: 17/12/1998

DOI:

10.26481/spe.19981217fd

Document Version:

Publisher's PDF, also known as Version of record

Please check the document version of this publication:

- A submitted manuscript is the version of the article upon submission and before peer-review. There can be important differences between the submitted version and the official published version of record.

People interested in the research are advised to contact the author for the final version of the publication, or visit the DOI to the publisher's website.

- The final author version and the galley proof are versions of the publication after peer review.

- The final published version features the final layout of the paper including the volume, issue and page numbers.

Link to publication

\footnotetext{
General rights rights.

- You may freely distribute the URL identifying the publication in the public portal. please follow below link for the End User Agreement:

www.umlib.nl/taverne-license

Take down policy

If you believe that this document breaches copyright please contact us at:

repository@maastrichtuniversity.nl

providing details and we will investigate your claim.
}

Copyright and moral rights for the publications made accessible in the public portal are retained by the authors and/or other copyright owners and it is a condition of accessing publications that users recognise and abide by the legal requirements associated with these

- Users may download and print one copy of any publication from the public portal for the purpose of private study or research.

- You may not further distribute the material or use it for any profit-making activity or commercial gain

If the publication is distributed under the terms of Article $25 \mathrm{fa}$ of the Dutch Copyright Act, indicated by the "Taverne" license above, 
Instructietechnologie en innovatie van probleemoplossen: over constructiegericht academisch onderwijs 


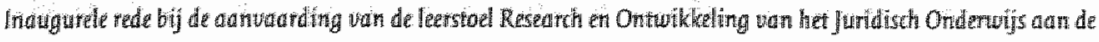

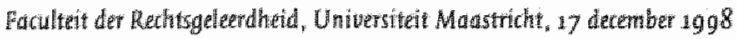


Instructietechnologie en innovatie van probleemoplossen: over constructiegericht academisch onderwijs

Prof. dr. E. Docley 


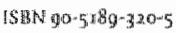

NuO 729.69

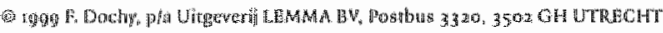

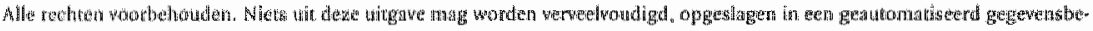

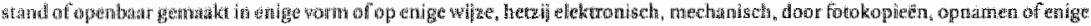

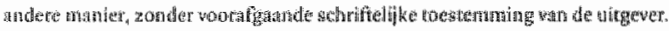

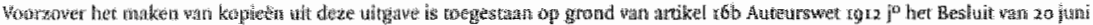

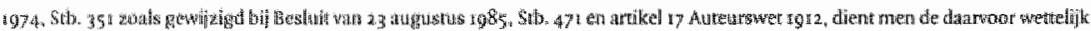

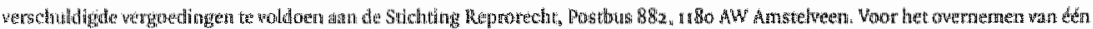

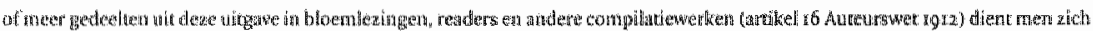
tot de anigererer wender.

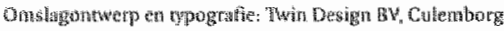


In Nederland is het de gewoonte bij de anvaarding van een niewwe leerstoel zijn visie daarop in een openbare rede kenbaar te maken. Het is echter niet allijd even gemakkelijk om zijn visite over te brengen en het is ook lang niet alijd duidelijk of het publiek de boodschap na een dergelijke rede meedraagt.Bij mijn lezingen geef ik daarom wooraf aan wat de boodschap is en wat de doelen zijn.

Mijn boodschap luidt als volgt:

$x$ in het juridisch onderwijs zal de toepassing van instructietechnologie nog sterk toenemen;

2 innovatieve strategieën voor probleemoplossen en innovatie van $\mathbb{P G O}$ via constructiegaricht onderwijs maeten onderzocht, ontwikkeld en geïmplementeerd worden;

3 aok woor het onderwijs in de Rechtswetenschappen geldt dit.

Daarnaast heb ik nog de volgende persoonlijk doelen woor vandaag (met andere woorden wat wil ik bereiken):

I dat u als geinteresseerde toehoorder geboeid wordt door mijn betoog;

2 dat de kembegrippen van het betoog onthoudt: instructietechnologie, constructiegericht onderwijs, probleemoplossen en juridisch onderwijs;

3 dat de relatic tussen deze kernbegrippen duidelijk is.

Bij mijn collega"s en vrienden-juristen heb ik herhaldelijk onderwonden dat ze voornamelijk interesse hebben in drie zaken: de politieke actualiteit; het universitaire beleid en de beleidsvoering in het algemeen, en culinaire, epicuristische bezigheden. Dararover zullen we het ook nu hebben.

\section{Opbounu}

De opbouw van het betoog is als wolgt:

Eerst geef ik enkele beschouwingen over de rechtswetenschappen c.q. de rechtspraktijk, daarna over het universitair onderwijs. Daarbij poog ilk aan te tonen dat de faculteit der Rechtsgeleerdheid (FdR) van de Universiteit Masstricht (UM) al lang niet meet" de traditionele faculteir is war de meeste toehoorders hiex aan denken en dat het probleengestuurd onderwijs (PGO) zich verder zal moeten ontwikkelen in de richting vath 
het zogenaamde constructiegericht onderwijs (CGO). Daarna zal ik het opeenvolgend hebben over de instructietechnologie, de research, het management van universiteiten en innovatiestrategieedr. 


\section{Het huidige rechtssysteem}

We verkeren in een periode dat het rechtssysteem pooral in Belgie an veel kritiek onderworpen wordt. Ook het politionele systeem. De kritiek wordt nog schrijnender door de reacties van zij die de topvrouxw was an dat systeem, namelijk Mr. Liekendael. Mogelijk een laatste sparteling van een zichzelf veranderend systeem, maar in realiteit wellicht slechts een topje van de ijsberg. Nog nooit is het gerecht zo geschaad als op hev moment van de ontsnapping van Dutroux. En op 28 december 1998 wa men in het gerecht weer een milpaal bereilken. Op die dag verjaart de strafrotdering in de Securitas-zaak. Concreet betekent dit dat veertien zware jongens met een gerechtelijk verleden strafrechtelijk wrijuit zouden kunnen gaan, ondanks het plegen van wier gewelddadige overvallen op Securitas-geldtransporten in 1987 en 1988 . In extremis is een wets wijziging nodig geweest op dit te voorkomen. De oplossing wan de regering? bolitie en gerecht herstructureren.

of het juridisch systeem in Nederland beter is, is een vragg voor een nuttige discussic met mijn collega's. Over het Nederlands juridisch systeem zal ik mij niet uitspreken. daar zijn diverse van mijn collega's beter geplaatst woor.

Ik stel alleen wast dat er minstens barsten in het systeem zijn te constakeren. Het rapport Van Traa bijyoorbeeld toont dit aan en de bevindingen over het functioneren van de diensten lijken soms erg op de bevindingen van de commissie Dutroux. De commissie Van Traa onderzocht de 'methode' wan Justitie om drugslijnen op te rollen. 'Methode" krijgt hier een bijzondere betekenis want het betekent dat gefinancierd door de overheid en met medeweten wan politie en justitie voor miljoenen aan drugs Nederland binaen kwamen en werder werden werhandeld.

Andere woorbeelden zijn de affares rond het Gromingse Openbatr Ministerie. Het functioneren wan het Groningse OM is zwatr onder vuur komen te liggen toen bleek dat de Hoofdofficier van Justitie ofwel te lat liet ingrijpen (de kwestie van de Ooster" park rellen) of weel te hard liet ingrijpen (de affaire Lancee). De nan bleek werwolgens een onderzoek naar de oorzaken van de Oosterpark rellen te hebben uitbesteed aan een bureau waarsan hijzelf Commissaris was. Dit noemt men in Nederland allicht en Belgische situatie. In jeder geval heeft Nederland ook op politiones vlak met op zijn ninst 'vreemde' situaties te maken gehad. 


\section{ITet universitair onderwijs}

Ben matechappelik systeem veranderen is niet eenvoudig. Zeker niet als er ook nog weinig midelen zin. Het antal magistraten bijwoorbeeld telt in Belgiê nu 2070 . Hoe wel de werlast nu viermal 20 hoog ligt als 50 jaar geleden, is het antal magistraten in die periode slech ts bifina verdubbeld. Justitie wil nu 240 nieuwe magistraten aanwerven. Verandering is uiterst moeizaam, tenzij er zich iets voordoet zoals op donderdag 23 aprill rgg8. Vier weken later al was er een globaal akkoord woor de volledige hervorming wan justitie en politie (het historische Octopus-akkoord). Dat "iets' was witerard de ontsnapping van Marc Dutroux tijdens het inkijken van zijn eigen dossiers. "Dutroux' is op die dag en internationaal begrip geworden.

Voor de zojuist geformulleerde kritiek op het functioneren wan de juridische diensten wordt langs allerlei wegen gezocht naar oplossingen. De weg van de opleiding van academici is uiteraard één d®arvan: juristen opleiden die efficiënt problemen kunnen oplossen, die efficiént kunnen werken en die probleemloos kunnen omgaan met informatietechnologie.

De Rechtsfaculteit van de Universiteit Maastricht is daar reeds gernime tijd mee bezig. Een verbinding tussen de juridische praktijk en de rechtswetenschap is eén van de nitgangspunten. Hoe wordt dit in het universitair juridisch onderwijs worm gegeven?

Maastricht heeft het profiel van een universiteit met probleemgestuurd onderwijs (PQO). Dit onderwijsmodel komt uit de McMaster en Case Western Universiteiten, in hoofdzalk uit de medische richtingen, wat het een kwarteeuw geleden werdingewoerd. De Mastrichtse juridische faculteit heeft zoals de andere faculteiten werder gebouwd op dit model. Mar juridisch onderwijs kende ook zijn eigen onwikkelingen. 20 wijs ik op het fenomeen lawteach (Tribe \& Tribe, 1987).

Als ik 'at raridom' enkele onderwijsgroepsbijeenkomsten in de juridische faculteit bekijk, dan zie ik wak de Lawteachmethode: intensief vragen stellen in kleine groepen; uitgaande van concrete taken, en streven naar het ontwikkelen wan een "anchor point" om hierop verter te bouwen. Ook hier zou men kunmen zeggen dat het doel reeds was een zekere "constructie" op te bouwen. 
Sinds jaren wordt probleemgestuurd onderwijs ook gebruikt in interactie met andete conventionele onderwismethodes (Feletti, 1992). De meeste Australische uniwersite iten hanteren in hun Law Schools de "problem method" op die wijze. Studenten krijgen hypothetische probleemtaken die ze oplossen op basis wan hun kemis. Dit proces omvat drie stappen: het bestuderen van het probleem, het gebruik van cursusmaterial en andere bronnen, en een discussie in de groep over de oplossing (Ogden, 1984 ). Ogden (1984, p. 655) stelt "Well-written problems of this nature can tap students" knowledge of substantive law, develop their abilities to analyse and value, and encourage the development of lawyering skills and professional judgement'. De vraag is of wat Ogden noemt wel wordt bereikt met 'de problem method' alleen?

Welke ideeën moeten aan dk basis liggen wan een juridisch onderwijsmodel? Voorkennis van studenten is de sterkst bepalende factor voor het leren. (Dochy, 1992). Dit impliceert dat studenten in de Rechten de noodzakelijke wookkennis zo efficiènt mogelijk moeten opdoen, om een kennisbestand te kumen construeren, een casus gericht re kunnen oplossen en relevante vaardigheden te kunnen werwerven. Naast de basiskennis van de discipline, toepassing van deze basiskennis en de vaardigheid in het probleemoplossen, zijn schriftelike en mondelinge communicatievaardigheden van groot belang (Dochy \& Van Luyk, I987). Men moet daarbij denken aan schriftelijke commanicatievaardigheden als: een verhandeling over een juridisch thema kumen schrijven; rechterlijke teksten kumen opstellen zoals pleitnota's, contracten, et cetera; cen juridische tekst kunnen synthetiseren; een juridisch wetenschappelijke tekst kunnen lezen en bespreken; schriftelijk kunnen adviseren lop een wijze die voor de client helder is); een schriftelike argumentatie kunnen geven; een eigen standpunt innernen, verdedigen en kumen anticiperen op tegenargumenten; een vershag kunnen maken (van cen vergadering, lezing, betoog, et cetera) en kumen participeren in een elaktronische nienws- of discussiegroep.

Voorbeelden van relevante mondelinge communicatievaardigheden zijn: mondeling kunnen adviseren (op een wijze die voor de cliënt helder is); de essentie uit een gesprek kunnen thaler: cen presentatie kunnen geven over een jurdisch onderwerp; een stand. punt kunnen geven, beargumenteren, verdedigen, beoordelen en inspelen op tegenargumenten; advies-en slecht nieuws gesprekken kumen voeren; actief kunnen deelnemen aan en vergadering; kunnen onderhandelen en overeden en multidsciplinair kunnen samenwerken.

Welke onderwijsmethode(s) is (zijn) nu het meest geschikt om deze uitgangspunten concreet vorm te geven? Hierover handelt de volgende paragraaf, 


\section{The new era': van PGO naar CGO}

\subsection{EEN KWARTEEUW PGO}

PGO stat meestal voor probleemgestuurd of soms probleemgericht anderwijs. In ons geval academisch onderwijs: witgande van reële problemen en rekening houdend met de realiteit wan het bedrijfirleven en de maatschappelike instellingen. Alle onderwijs is meestal in blokken ingedeeld, waarbij in hoofdzak probleemtaken het uitgangspunt ziln voor het leerproces in kleine onderwijsgroepen. In de laatste 25 jaar (vanaf 1974 aan de Universiteit Mastricht) (Dochy \& Wijnen, 1987) heeft deze onderwijsvorm zijn woordelen bewezen in vergelijking the het traditionele onderwi |s: de praktijkrelevantie wan de opleiding, de beheersing van academische wardigheden door studenten en de behoorlike parate kennis van studenten (uiteraard opnieww vergeleken met traditioneel onderwijs en niet gepeild op examenmomenten). Dit PGO heeft in de praktijk ook een aantal madelen laten zien: de hoge onderwijslast woor docenten, het tekott an groepsbinding in de onderwijsgroepen door hetontbreken van een gemeenschappelijk doel, de lage productgerichtheid wan studenten, een te laag aantal studie-uren, enzovoorts. Wellicht is het wenselijk om hieraan te schaven.

\section{2 NIEUWE ONTWTKKELINGEN: DE WEG NAAR CGO}

CGO staat voor constructiegericht onderwijs. Heronder verstaan wij: een op de weternschap (in casu Rechtswetenschap) gerichte optimale mix wan onderwijswomen, met name opdrachtgesturur, asusgestuurd en probleemgestuurd, ontwerpgericht, productgericht en actiegericht onderwijs dat ans en de domenspecificiteit van de (Rechts-)wetenischap. Dat betekent dat er in eerste instantie en duidelijke sturing uitgat van het onderwijs. Die sturing start bij een duidelijk omschreven opdracht, een casus uit de praktijk die opgelost dient te worden of een kort probleem warwoor cen oplossing moet komen. Het betekent ook dat men zich moet richter op een doel, zoals her nitwoeren van welbepalde activiteiten of her maken van een ontwerp, model of product. Voor de rechtswetenschappen zal dit bijwoorbedd een beargumentering zijn, een pleidooi schriven, een opstel over een bepaald thema schrijven of de jurisprtidentie met betrekking tor een bepallde casus op een rij zetten. 
Leidnad is dat de student kenns construeert, academische vaardigheden opdoet en productgericht werkt. Het gat om Constructiegericht Onderwijs (CGO). Pet- en co assessment en overall-assessment maken integral deel uit van 600 , watrbij studen ten een rol vervullen in de evaluatie (zie verder).

Kern van het $\mathrm{CGO}$ is het productgerichtwerken in groepen dat start wanut een concre te opdracht of een casus, een probleem dat werwaring sticht. Verwarring leidt tot interesse, op woorwaarde dat men in die wewwarring anknopingspunten kan vinden in zijn voorkennis. Met andere woonden; de kloof tussen de voorkennis en het doel noet overbrugbaar zijn.

Als wat we moeten leren kant en klare sukken wetenschap aijn, zonder relatie met een casus of een duidelike actie, zet het aan tot reproductie en, jammer genoeg, meestal ook tot inflexibel denken. Dit is vergelijkbar met het verhaal van de atme Nastudin. Nasrudin trok elke dag mer zin ezels en een kar vol stro over de grens. Bij terugkeer gaf hij telkens aan de douanebeambten toe een smokkelaar te zijn. Telkens werd hij grondig onderzocht. Ze zochten in het stro, staken het soms in brand, zochten in zijn klew ren, de kar, maar wonden niets. Nastudin werd wel steeds rijker en ging rentenieren in aan naburig land. Een ambtenaar kwam hem daar tegen en vroeg hem wat hij de hele tijd smokkelde. 'Ezels', antwoordde Nasrudin.

Inflexibel denken, niet in staat tot een ander denkproces. Vele problemen kunnen niet worden opgelost op basis van algoritmen, maar vagen een flexibel gebruik van kentits.

Waarom leren situdenten dan beter in CGO? Door de sterkere motivative en de praktilkrelevantie? Ondermeer, maar hiermee bouwt het verder op de verdiensten wan het PGO. Ook de afwisseling in werkormen, indien die afwisseling uitgat van een beleid en gebaseerd is op de 'constructiegerichte' visie, dragen ertoe bij. Hoe verder de student vordert in de studie, hoe meer zelfstudie en zelfstandig probleemoplossen men an hem kan overlaten, zolang in het product duidelijk wordt dat het doel is bereikt en zolang dit op een adequate wijze in de assessment an bod komt.

Matr vooral door het samenwerkend leren, de groeps buinding (en sociale controle) en de sterke productgerichtheid. Deze laatste twee kenmerken worden door het PGO vellal niet wargemakt. Indien er geen gerichtheid is op een gemeenschappelijk product, is er geen gerichte samenwerking en te weinig interactief leren. Indien dit proces net effectief verloopt, blift de student wak weg. Dar betekent echter miet dat meer hoorcolleges per definitie een oplosing bieden; de praktijk wijst uit dat studenten daar juist ook wegblijven en dat het leerrendement (op korte en zeker op lange termijn) wrij laag is.

Studenten worden ook geconfronteerd met de producten van andere groepen die ze gaan bestuderen, beoondelen, bespreken en presenteren. Dit impliceert een actief gericht kennisconstructieproces zoals bijwoorbeeld het inpassen wall nieuwe informa" tie in bestaande schema's. Wat betekent ru dit inpassen wan informate in schema's? 
Als ik u zou viragen om mil na afloop van deze rede te vertellen wir welke onderdelen een functioneel dataontwerprapport bestaat zou dat niet eenvoudig zijn. Dit onderwerp breng ilk niet ter sprake en u bezit niet ower het kader/framework waar deze informatie in past.

Het zou ook moeilijk zijn om bijvoorbeeld deze tekst te onthouden die John Bransford (r979) gebruikte. De tekst kan een introductie zijn van een moordscène. Als jurist moet u de verdediging voeren. Indien ik u zow vragen de tekst te lezen en mij daarna vragen te stellen over de omstandigheden van de moord, dan krijgt u het wellicht bijzonder moeilijk. In het onderzoek van Bransford bleek dit voor wrijwel alle studenten moeilijk te zijn. De meeste studenten gaven aan dat de tekst onbegrijpelijk is.

If the balloons popped, the sound would not be able to carry since everything would be too far from the correct floor. A closed window would also prevent the sound from carrying since most buildings tend to be well insulated. Since the whole operation depends on a steady flow of electricity, a breal in the middle of the wire would also cause problems. Of course the fellow could shout, but the human voice is ntot loud enough to carry that far. An additional problem is that a string could break on the instrument...

Dat was niet meer zo nadat ze het passend schema hadden gezien dat de context geeft voor het begrijpen van de tekst. Als u het passend schema ziet wordt dat veel eenvoudiger (Zie figuur $x_{\text {; }}$ overgenomen van J. Bransford, 1979).

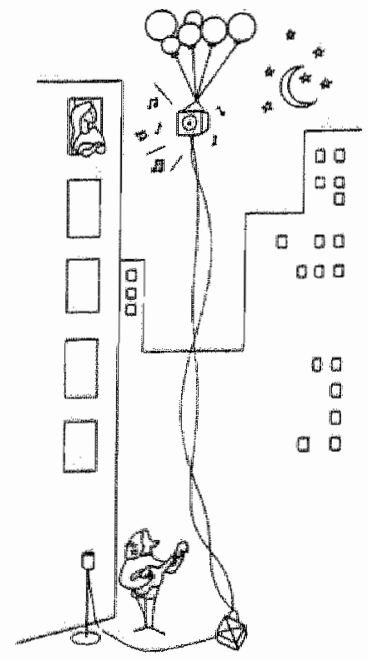

Higutr I Romed in Jullin 
Schank \& Abelson deden gelika ardig onderzoek met laet "Resturant Script". Dat schema beheerst $u$ allen. Blke tekst die op dit schema is gebaseerd wordt door u evinouding gezien daar het u bekend is wat er gebeurt als u een restaurant binnenstapt. Het schema ziet er dan bijwoorbeeld als volgt uit:

De baas neemt ww jas aan, biedt u een aperitief nan in de salon, brengt u de menukart en newt way

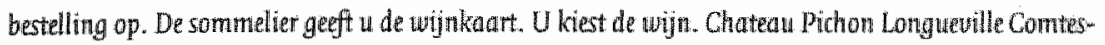
se de Lalande 1987 . De ober vraggt u aan tefel. Hij brengt u het woorgereht. U progft de winn en keurt die af. De tweede fies is uitstekend. De ober brengt u de hazenrug, daama he assortiment wan Belgirthe kazen en de sabayon wan Niepoort Ponto en Hoegaarden met gemarinerde peertjes en santle ijs op grootvaders wijze. Bij de kop thee vragat u eeth Calvados en de rekenitug. Uw creditard zorgt wor de rest. Uw jas doet eng goed op deze winterawond. De responsible young drivers brengen uneilig thuis.

\section{Wat leten we hieruit?}

I. Kennis is contextgebonden. Je kan inhouden beter onthouden op bas is van gebeurtenissen, als je de context kent die betekenis werleent.

2 Relevante woorkennis maakt begrijpen mogelijk.

Om aan kennisconstructie te kumen doen, hebben we behoefte an de passende schema's en voorkennis. Consiructiegericht onderwijs gaat dus uit van 'situated learning" en constructie van kennis door de studenten. Glaser and De Corte stellen (in Dochy I992, p.I): "Indeed, a well-organized and coherent knowledge base initiates inference, conceptualization and the acquisition of principled understanding. (...) One of the central findings of educational research of the past fifteen years is that a key to developing such an integrated and generative knowledge base is to build upon the learner"s prior knowledge. (...) Indeed, new learning is exceedingly difficult when prior informal as well as formal knowledge is not used as a springboard for future learning. It hats also become more and more obvious, that in contrast to the traditional measures of aptitude, the assessment of prior knowledge and skill is not only a much more precise predictor of learning, but provides in addition a more useful basis for instruction and guidance, $^{\prime}$

\subsection{ASSESSMENT ALS BOUWSTEEN: AUTHENTTEKE ASSESSMENT EN ASSESS- MENT METHODOLOGIE IN CGO}

Op lagere onderwijsniweans is gesproken ower het intichten van 'Krachtige letrongewingen' (De Corte, 19go). Als kenmerken wan een krachtige leeromgeving knumen we aangeven:

- leren is belangrijker dan doceren;

- authentieke situaties zijn her uitgangspunt;

- toepassing is het ultieme doel;

- coöperatiefleren; 
Krachtige leeromgevingen 2 inn dus onderwigssettimgs warbij wordt vitgegan wan authenticke situaries, problemen, casussen en opdrachten, die tot doel hebben de studenten kenis en vaardigheden te leren toepassen in een proces van samenwerking met medestudenten. Het belangrijkste bij een innovatie in die richting is dat de examinering als bouwsten fungeet: Anders gezegd: examens zin het sterkst sturende aspect van de activiteiten wan studenten. Daarom is het noodzakelijk om toetsen te laten aansuiten biy de opzet van het onderwijs. Dit betekent dus dat toetsen ook constructiegericht zifn en niet alleen reproductiegericht. Examens moeten dus uitgaan van authentieke situaties, problemen, casussen, opdrachten en ontwerpen, die tot doel hebben de studenten kennis en wardigheden te leren toepassen. Dü betekent dat we terecht komen bij de in de literatur genoemde 'Authentieke Assessment' (Birenbaum \& Dochy, x996). Een goed voorbeeld daarvan is de OverAlltoets, een casusgerichte toets die op basis van reelle casulistiek toetst of studenten in staat zinn hun kennis toe te passen om het gestelde probleem op te lossen. (Segers, 1992, 1997).

Het tijdperk van het vitsluitend memoriseren en reproduceren is voorbij, studenten moeten ook iets kunnen. Ook dagvardingen schrijven, dossiers onderbouwen en argunienteren. Dat zou ook geěvalueerd moeten worden.

Duidelijk is dat de assessmentmethodologie van morgen meer gericht moet zin op het beoordelen van kennisconstructie. Het gebruik van een OverAlltoets (Segers, rg92; 1996; 1997), zoals die wordt toegepast aan de economische faculteit en diverse andere faculteiten in het land, en de casusgerichte toetsen aan de Australische Law Schools, zijn hier voorbeelden wan.

Elke vorm van vernieuwend universitair onderwigs is gedoend te mislukken als aan deze basisvoowaarde, met name de aansluiting vam toetsing en onderwijsopzet, niet voldlaan is. Studenten zijn economisch denkende en weelal effectief werkende wezens (hoewel ze soms aan andere dingen werken dan hetgeen wij voor ogen hebben). Dat betekent dat ze na een eerste keer (die meestal goed gaat), zich niet meer laten verleiden tot onderwijgroepsbijeenkomsten wanneer het nut of de opbrengst daarvan niet duidelijk is (in termen wan examenopbrengst). Met andere woorden: dat wat getoetst wordt (de doelen) mout in de onderwijsgroepen geleerd worden en omgekeend. Darrbij is de bepalende keuze vooraf gemaakt: we leiden "reflective practitioners" op, die basiskennis beheersen en kumen toepassen in functie van te analyse en de oplossing van casuilstiek en die kermaardigheden beheersen. Kerrvardigheden in COO zijn: analyseren, synthetisenen, problemoplossen, efficiënt informatie opzoeken, informatie selecteren, gesprekken leiden, een vergadering woorzitten, adviseren, argumenteren, efficient werken en andere eerder genoemde juridische wardigheden.

In CGO zal zowel de assessment, het toepassen wan basiskennis en her beheersen wan 
academische vardigheden, als de integratie wan vakgebieden andacht moeten krijgen. Dat zal onderneer zijn besiag kunnen krifgen in het wetsen win het leerproces en het door studenten op te leveren product.

Belangrijk is ochter dat criteria voor assessment duidelijk zijn; wowel voor kennis en toepassing van kennis als voor vaardigheden. Enkele voorbeelden kunnen dit duidelijk maken.

In een examen binnen het juridisch onderwis zouden de volgende vragen kunnen woorkomen:

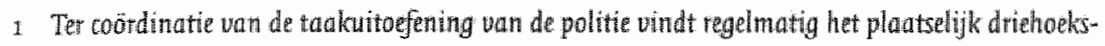
overleg plaats. (R. Wolleswinkel, 1998)

Wie nemen and dit overleg deel?

a De burgemeester, de korpschef van polithe en de officier von justitie

b De burgemeester, de korpsthef varn politie en de polittierechter

c De burgemester, de officier van justitie en de politierechter

a De korpschef van politie, de officier van justitie en de politierechtert

2 Heros maakte zich schuldig aan het verstoren van en godsdienstige bijerkonst, temeinde de deelnemers aan die bijeenkomst te warschwwen voor de brand die in het kerkgeboutu was witgebroken. De afficier van justitie vervolgt Heros tot diens verbazing wegerss overtreding war artikel 14.6 Strafrecht. Heros is wan mening dat het belangrijker was om de ketkgangers te wadrschuwent dan om ze ongestoond hun bijeenkomst te laten woltooien. De rechter accepteent dit verweer wan Heras. (Bal, P., 1998)

Wat moet de rechter dan doent:

a Hij moet Heros ontslaan war alle rechtsvervolging, ondat daze de zwaarst wegende plich heeft gehoorzamid

b Hij moet Heros weroordelen, matr tewens gebruik makent van de mogelijkheid om geen straf op te leggen (atrikel ga Strafrecht)

c. Hij moet Heros veroordelen, ondat artikel 146 Strafrecht geen witzondering maaket woor dergelijke noadgevallen

d Hij moet Heros urispreken, omdat deze de zwadrst wegende plicht heeft gehoorzamd

U neemt van mil aan dat deze magen juridische kennis pellen (feiten, inzicht en toepassing van basiskennis). Het criterium us ook vrij duidelijk. Over een correct antwoord is weinig discussie mogelijk. Wat betreft juridische vardigheden is dat anders.

3 Schriffeen pleitnota op basis van het bijgevoegde dossier "Bou wperikelen Vandamme"

4. Mak cen contract woor de samenuerking tussen Mawrissen N.V. en Clerix B.V. zoals beschreven in de casus 'Psychatheropiebed rif gant fors uitbreiden vio werkgeversorganisotie' 
Over hei antwoond op de vragen 3 en 4 is heel wat discussie mogelifk als de criteria niet vooraf duidelijk zijin. De criteria waaraan cen goede pleitnota en ex contract moeren voldoen zullen op voorhand moeten vastliggen.

Wellicht wordt dit nog duideliker met een woor u bekend onderwerp (los wan uw diseiplinel. Drobeert a de volgende vagen te beantwoorden en na te gaan wat de wolgende veagen peillen:

a Welke druif is de belungringste in Pomerol?

b Hoe verschillem de Zuid-Franse wijnet van die van midden Frankrik?

c Wat is je oorded over de kwalteteit van de wijn en zijn oorsprong?

Vaag al peilt feitenkennis. Het antwoord is de merlondruf. Vuag b) peilt inzicht. Het antwoord is dat zuidelijke wijnen meer alcohol en minder zum zullen bevatten als gevolg wan de verschillen in gisting welke weer veroorzaakt is door de rol die de zon en de ondergrond spelen in het rijpingsproces. Vraag c) peilt uw vardigheid in het beoordelen van wijn. U merkit dat u in ieder geval de vraag niet kunt beantwoorden zonder de wijn in kwestie te proeven. Daar is een oplossing woor. Namelijk de wijn ontkurken. Verolgens kunt u hem proeven en beoordellen.

Wanneer ilc twee collega's eenzelfde wijn laat proeven, kunnen hun meningen over de kwaliteit van de wijn ver uiteen lopen. De mening of zil zelf de vardigheid beheersen on wijn te beoordelen, kan ook wer uiteenlopen. Dit is het geval wameer we niet op voorhand de criteria duidelijk maken die door wijnexperts gebruikt worden woor het degusteren van wijn.

Ook bij het beoordelen var vaardigheden in het onderwijs kan dit. Men komt dan tot de constatering dat de oordelen wan werschillende mensen sterk uiteenlopen qua inhoud, met name ondat de beoordelingscriteria niet duidelijk zijn. Het vastleggen wam criterial is essentieel bij het beoordelen van vaardigheden (Dochy \& Moerkerke, 1997; Moerkerke, 1996 ).

De veranderingen in de taken van de student en de taken van de onderwijsinstelling/docent geven aan dat de beoordeling ook niet meer alleen in handen wan de docent hoeft te liggen. Studenten worden beschouwd als zelfistandige, attonome en inituriefijke individuen die ita grote mate zelf hun leerproces kunnen sturen (Sluijsmans \& Dochy, 1998). Kennis an vaardigheden (competenties) worden bij woorkeur njer overgediagen wia reproductieve technieken, maar op actieve wijze door studenten verworven (geconstrueerd). Veel kennis is immers contextueel (situationeel) bepaald. Door de metrenschap en de beroepspraktijk zo goed mogelijk in de leeromgeving te weerspiegelen lkan en betekeniswolle context voor kennisverwerving ontstawn (Brown, Collins \& Dugid, 1989). De student zou ook kritisch moeten leren kiken naar eigen handelen, leetproces, productgertichtheid en zijn eigen inhoudelijke kennis. De beoordeling zal in het $\mathrm{CGO}$ als krachtige leeromgeving niet alleen gericht zijn op her 'afrekenen' van de student, maar zal ook een rol kunnen krijgen in het structureren en moni- 
toren wan het leerproces. De mogelike toetwormen die hierbil kunnen helpen worden gevat onder de term 'wieuwe toetswormen'. Deze instek wan assessinent vaagt eerden om een analyse van de sterkten en zwakten wan de kennis en vaardigheden, dan on toetsen die toteen simpele eendimensionale score leiden. Vanuit dat gezichtspunt passen ze ook goed bij de kenmerken van het juridisch metier.

Bovendien is het onmiskenbaar dat men bij onderwijsinnovaties veelal weranderingen doorvoert en pas later gaat denken aan de toetsing. Gezien het feit dat de toetsing de meest sturende factor is voor studenten, is thet mogelijk dat de vernieuxing aan kracht zal verliezen omdat studenten niet geneigd zijn inspanningen te leveren die niet worden beloond. Een eerder geconstateerde valkuil (zoals door de auteur zalf erwaren) is dat het onderwiss wordt ingericht als krachrige leeromgeving (wannit constructiegew richt onderwijs), maar dat traditionele toetsing wan in hoofdzalk feitenkennis blift primeren. In voorkomend geval vertonen studenten de meiging de onderwijsgroepen niet. bij te wonen, geen inspanning te leveren om authentieke problemen op to lossen en zich niet te richten op een bepaald product maar zich te richten op het memoriseren van de volgens hen relevante literatun. Studenten zijin in dat opzicht steeds economisch denkende mensen.

In het huidige onderwijs zijn veel verschillende soorten toetsen te onderscheiden, veelal gericht op het toetsen wan kennis. Voorbeelden zijn de toets met open vragen, het essayexamen, de meerkeuzetoets en combinaties hierwan. In nieuwe toetswormen wor den studenten beoordeeld op hun basiskennis maar ook op basis van hun actieve prestatie om kennis op een creatieve manier te gebruken om problemen op te lossen, het leerproces te beworderen en kritisch te evalueren. Deze problemen zijn reelle problemen, authentieke representaties van problemen in de werkelijkheid. Voor grote groepen studenten zal dan witeraard toetsautomatisering bowenaan de lijst staan. Casusgerichte assessment zoals de OverAlltoets is goed bruikbar binmen eenwoudige assessmentsofware zoals "The Examiner".

In het juridisch academisch onderwijs worden diverse vormen van assessment gevonden. Onderzoek naar het gebruik van dergelijke nieuwe toetswormen is elders gepubliceerd (Birenbaum \& Dochy, rg96, Falchikow \& Boud, r989; Sluismans \& Dochy, r998). De bruikbarheid en effecten van bijvoombeeld selfassessment, peer-assessment in onderwilsgroepen, product assessment, portfolio assessment, en casusgerichte (at of niet geawtomatiseerde) toetsing zilin nutrig om wender te onderzoeken.

\section{4 CGO ALS ONDERWIJSBELEID}

Casusgestuurde instructie, opdrachtgestuturde instructie, ontwerp en productgericht onderwijs, interictieve elektronische werkgroepen, elektronische begeleiding, virtuele leer- en oefenomgevingen, zelfstudie en activerende colleges kunnen deel uitmaken vam een CGO leeromgeving, maar dan wel in cen weloverwogen onderwijsbeleid. 
Aan inspiratie woor casussen kan het niet ontbrekent de Commissie Van Trad, de commissie rranchimont en het ontslag van professor Chris van den Wingaer daarin, Europa en de Euro, de affaire Xir de affare Lancee, de Agusta-Dassaul affatre, de zaalk De Statke, de Bende wan Nijwil, whwassen in Belgie (een witemate interessant item voot Nederlandersis, ercera.

Dit laak niet staan dat het grootste probleem bif de implementatie van CGO het curriculumontwerp is. Om bovengenoende onderwijsonderdelen parallel enlof subsequent aan elkar te koppelen zal zowel een inhoudelitke als een yomelike afstemming nodig zifn. Ervaring leert dat studenten niet zelf wrerken aan een opdracht of probleem als ze weten dat de oplossing hen later verteld zall worden. De praktik laat ook zien dat het actief werken in onderwijsgroepen en het werken in een elektronische leeromgeving eerder leiden tot een meer actieve participatie dan instructiecolleges. Een dergelijk instructecollege moet dan ook een onmisbare plaats hebben in het total van het curficulum (om een snelle leegloop van het auditorium te voorkomen). Een everwicht tussen onderwijg in blokken (horizontaall) en onderwijs in stromen (verticalal) zal noodzakelijk zijn. Het is niet aan te taden orn deze twee stromen zoals in bepalde universiteiten los van elkate te ontwerpen. Het gebruik van instructetechnologische tools zal integratie van diverse stromen ten goede komen.

\subsection{DE INSTRUCTIETECH NOLOGIE}

"Thans kom ik op het terrein van de instructietechnologie. Het gebruik van nieuwe technologieèn in de universiteit neemt exponentieel toe en krijgen een platats in CGO. Daarmee ontstaan er nieuwe problemen en worden bestande opgelost.

Overigens, heeft a al in beeld wat het grootste probleem is van de zowel de Belgische als de Nederlandse justitie? De rechterlijke mach staat dusdanig onder tijdsdruk en werkt met een dusdanig tekort aan middelen dat vele zelfs zware zaken nooit woorkomen, zelfs verjaren. In België wil men nu zelfs wia een wetswijziging woorkomen dat het Securitas-dossier zou verjaren. Een mogelijke oplossing ligt wellicht in thet efficiènt gebruik van technologische middelen.

Latat ons ook ens kifken natr de bestaande (luxe-)problemen van deze faculteit. Een van de problemen wan deze Rechtsfaculteit is de owerpopulariteit. Hoe remmen we de massale instioom wan nietwe studenten af? Hoe lossen we de instroomproblematiek op orn de kwaliteit op peil te houden?

Oplossingen wan problemen zijn steeds te zoeken op drie wakken:

I datgene wat we vroeger ook al deden, namelijk bezuinigen (de bezuinigingsstrategie);

2 datgene wat nieuw is, wat we niet kennen, namelijk de technologie (de ICT strategie);

3 datgene war we niet aan dachten, namelijk de student zelf (de studentgerichte strategie). 
Wat we besparen door de bezuinigingsitrategie, zullen we moeten investeren in infrastructunt voor de toekonst (bezuinigingen zijn een korte termijn strategie, $1 \mathrm{CH}$ werkt op lange terminj. Investeren in infrastructurur lijkt sowieso onvermijdelijk Het "kotnet" in Leuven is daar een goed woorbeeld van. Met mame de uniwersiteit investeert. niet in hardware, maar ondersteunt dat alle studentenkamers woorzien worden van een Internetconnectie (c.q. intranetconnectie). Even belangrijk is het dat we rekening houden met de studenten en de hun geboden kwaliteit. Opmerkelijk is dat mijn studenten in Levven buiten de onderwhisgroepen meer werk verrichten dan gevragd wordt (in tegenstelling tot de richtlinen in de blokboeken) en dat $k$ de indruk krigg dat het in Mastricht eerder niet zo is. Misschien kumen we uit een wergelijking yan beide anpakken een en ander leren. Hier verwijs ik naar het eerder genoemde verschil PGOCGO. Niet alleen zal onze faculteit mijns inziens op temijn een beperking valu de instroom (c.q. bindend studieadwies) dan wel een fixus moeten overwegen voor stum denten, ook moet men rekening houden met de realiteit wan de studenten die succeswol zullen zijn. Over een paar jaar heef elke student zijn persoonijke website, heeft hij IAVA als het ware geintegreerd als handschrift, en ziet hij 'leren' deels als een elektronisch interactieproces tussen informatiedatabases met specifieke ICT-tools.

De student vraagt om:

I Een aan de informatiemaatschappij aangepaste didactiek gericht op academische kn juridische kennis en vaardigheden en een overeenkonstige assessmentmethodologie.

2 Aangepaste tools:

- communicatietools: e-nail, groupware and shareware;

- searchengines voor informatie; woor specifieke juridische databases; voor bookware; et cetera;

- leersystemen met ingebouwde begeleidingscomponenten (Martens, 1998);

- registratietools: inschrijfsystemen, volgsystemen; itembanksystemen; assessmentsofware;

- practicumtools, een systeem woor casusoplossen.

Woor specifieke tools zal zelf een design gemaakt moeten worden. Wellicht dat er woldoende reden is woor een eigen instructional design gericht op COO. De detaillering van het ontwerp en de ontwikkeling kan mins inziens dan best in samenwerking rot: diverse faculteiten, bijwoorbeeld met het Maastrichtse Learning Lab. Voor de implementatie zal immers een zeer nauwe betrokkentheid wan de faculteitsmedewerkers noodzakelijk zijn. Overigens moet men niet de fout maken on te proberen generieke sofware-applicaties te ontwikkelen die alle processen in bet onderwijs behelzen (cur susaanbod, woortgangsregistratie, toetsing, etc.). Het werleden heeft bewezen dat dergelijke systemen zelden opgeleverd worden, te duur zijn, en niet geïmplementeerd kunnen worden. Dat geldt niet voor systemen die specifiek gericht zijn op een onderwijsactiviteit, bifvoorbeeld toetsing. 
Is het nog te vroeg voor een implementatie van een dergelijke technologisch ontwikkeling? Wellicht niet. Kijken we in het eerste elektronische tijdschrift in het juridisch domein, dan zien we dat $\mathrm{E}$-Law startie in $\mathrm{z} 993 \mathrm{en}$ toen al artikelen publiceerde over het gebruik van elektronische tools in juridisch onderwijs. Binnen- en buitenlandse juridische faculteiten zijn werder die richting ingeslagen, zeker met als doel een extensivering van en interactieverthoging in het onderwijs.

Ook binnen de Faculteit der Rechtsgeleerdheid bestaan reeds waardevolle initiatieven in die richting. Met name het gebruik wan het Polaris-systeem (Ronteltap \& Eurelings, x 998 ).

Polaris is een leeromgeving waarbij rechtenstudenten wia de pc in groepen kunnex werken aan het oplossen wan taken, waarbij diverse hulpmiddelen worden geboden on te communiceren, informatie te zoeken, te plannen, te rapporteren en feedback te krijgen. Als er in de faculteit al gedacht zou worden man het verminderen wan de contacturen en her activeren van studenten buiten de contacturen, dan ligt hierin wellicht het aanknopingspunt. In Polaris worden studenten begeleid in een leerproces waarin ze actief kernis manipuleren, verwerken en construeren in een authentieke context. Het leren is coopperatief van aard en in een context van zelfstandig werken in groepen. Het systeem kan zo ingericht worden dat productgericht werken wordt ingebouwd. De taken zijn toegankelijk via Polaris. Na een groepsbespreking formuleren de studenten de leerdoelen. Daarna gaan ze individueel aan de slag en rapporteren hun bevindingen interactief via Polaris aan de groep. De tutor kan hierin sturen en toevoegen. Het systeem biedt mogelijkheden voor het genereren van owerzichten, de rode draad in discussies, et cetera.

In het blok 'Schade en schadevergoedingsrecht' is uit experimenten met Polaris gebleken dat studenten geconcentreerder en intensiever werken en dat men rapportages gebruikt ter voorbereiding wan de contacturen. Polaris heeft ook een sturend effect op het onderwijs, bijvoorbeeld het verplicht rapporteren voorafgaand aan de mogelijkheid tot lezen van bijdragen wan anderen. Daarnaast blijkt Polaris een effect te hebben van sociale controle in de groep, wat de activiteit stimuleert. De volgende 'screendumps' (Learning Lab Maastricht, 1998 ) geven een beeld van de opzet van Polaris. Aan een optimale werking van een dergelijk systeem zijn echter ook woorwaarden verbonden: er zal een goede infrastructuur voorhanden moeten zijn en een aangepaste begeleiding van studenten. Doelgerichte training en ondersteuning van docenten zal uitgebouwd moeten worden. Len vooraanstaande Rechtsfaculteit moet ook op dit vlak bestaande initiatieven werder uitbouwen. 

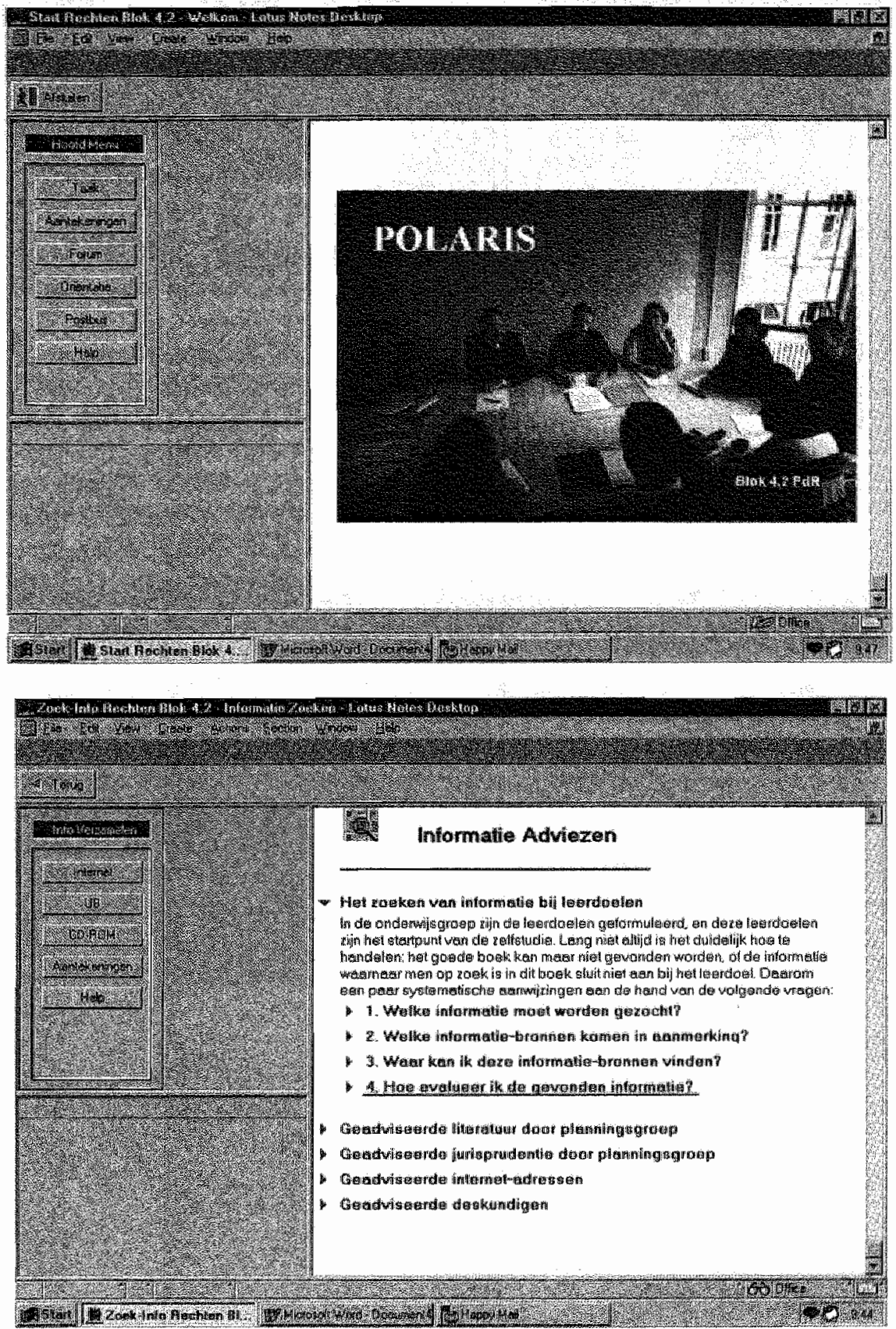


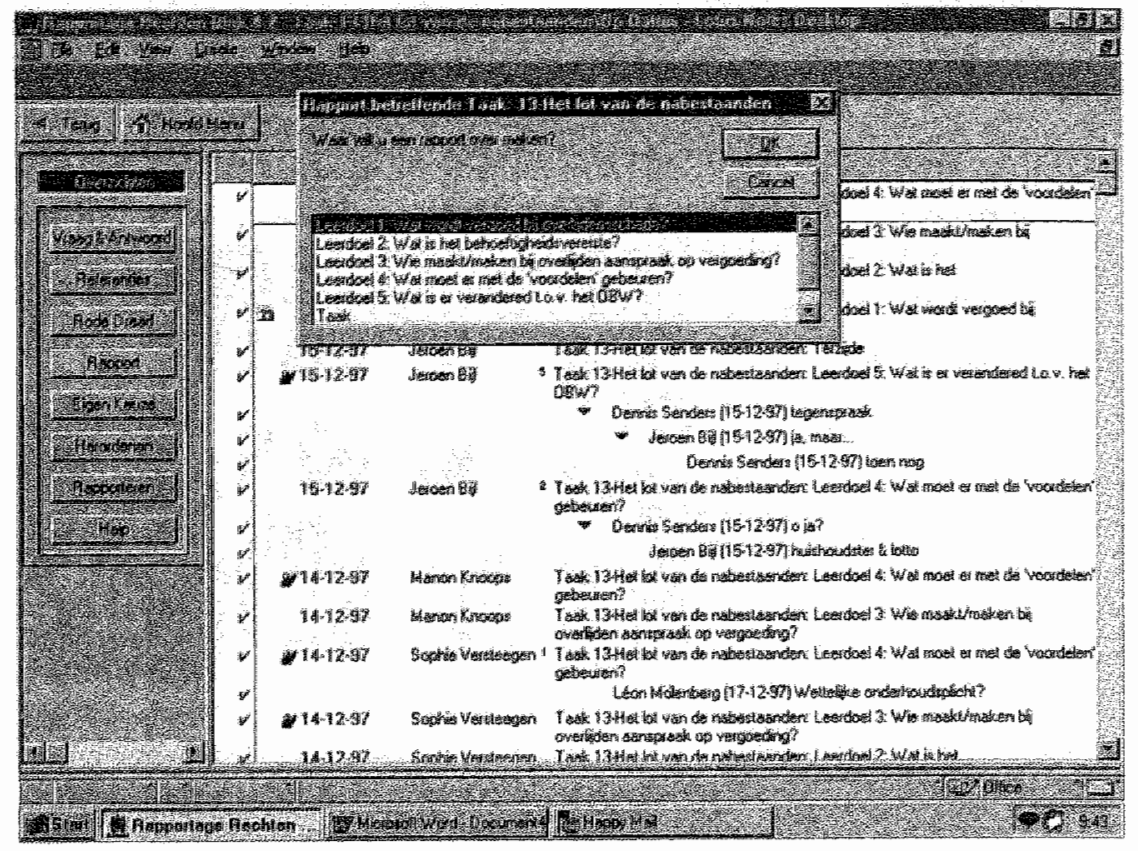

Pigutur es Scrutendumps polaris 


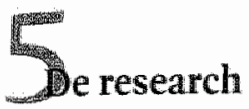

Research omvat vele facetten, zeker in de Rechtswetenschappen. Het varieert van de strafbarheid van commercieel dragmoederschap tot de effecten van bicameralisme. Daarnaast is er echter ook nog de research naar de kwaliteit van het juridisch onder wijs. Daar sta ik woor. Ik wil het daarom nog kort hebben over het onderzoek nar onderwilisprocessen en -kwaliteit.

Onderwijsresearchi is wat mij betreft gencht op optimalisering van het academisch onderwijs. Het gaat om de kwaliteit van het juridisch wetenschappelijk onderwijs. Een belangrijk kenmerk is dat dergelijke research zowel theoretische als empirische studies kan onwatten, maar steeds toepassingsgericht is en gericht op van te voren geplande producten en/of op het maken wan verantwoorde beleidskeuzes. Men richt zich dus op het zoeken naar betere methoden, het onderbouwen met harde data wan beleidsbeslissingen en het ontwikkelen wan instrumenten die optimalisering tot gewolg hebben, inclusief onderwijstechnologische ICT-toepassingen. 20 zal bijvoorbeeld het onderzoek naar studierendement en bepalende factoren ten aanzien van studie-nitval leiden tot beleidsbeslissingen over studieadviezen voor eerstejaarsstudenten. Experimenten met elektronische communicatie tussen studenten en tutoren leveren zo informatie over het te volgen implementatietraject en de nodige beleidsmaatregelen die hiermee gepaard moeten gaan. 
anagement van de universiteit en innovatiestrategieèn

"Quality assurance", is sinds mijn start hier aan de Universiteit Maastricht een hele tijd geleden, een topic gebleven in het universitaire en bedrijfsleven (Dochy, Wijnen \& Segers, 1987). We zijn geévolueerd van prestatie-indicatoren, naar standaarden zoals de $1 S O$ goo2-norm en tot stelsels van kwaliteitszorg.

De visitatiecommissies die nu 'audits' uitvoeren bezorgen de besturen de 'incentives' voor implementatie van innovaties. Innovaties als een verdere ontwikkeling van het huidige onderwijs, de implementatie wan ICT en de stimulering van kwaliteitszorgonderzoelk zijn dus voot elke faculteit eeta speerpunt in het beleid.

Het kwaliteitsdenken noodzaakt dan ook tot een managementaanpak zoals ik eerder heb beschreven in het boek Assessment Centres (Dochy \& de Rijke, rig95). Eenvoudig gezegd: aan elke activiteit ligt een projectplan ten grondslag met vastgelegde planning en producten.

En nog eenvoudiger gezegd: het bestuur van de faculteit zal krachtige beslissingen moeten nemen orn de kwaliteit wan het juridisch onderwijs blijvend te verhogen om enerzijds het uiterst positieve label van deze universiteit te behouden, maran anderzijds zich sterker te profileren ten aanzien var de juridische zusterfaculteiten, nationaal en internationaal.

Voor de implementatie van die innowaties kan bet beste worden uitgegaan van het 'A victory-model'. Docenten zullen:

- moeten geloven dat de instelling over voldoende tijd, kemnis, en hulpbronnen beschikt (Ability);

- moeten geloven dat men er waarde aan hecht (Value);

- over voldoende informatie moeten beschilkken (Information);

- de omstandigheden en het moment geschikt moeten achten (Circumstances \& Timing):

- de vraag moeten stellen: Hoe dwingend is het? (Obligation);

- de innovatie als aansluitend bij de heersende waarden \& normen moeten zien (Resistance)

- vooral naar hun voordelen die voortkomt uit de innovatie kijken (Yield). 


\section{Ter afsluiting}

Soms wordt mij gevraggd hoe het komt dat de $A B N$-Fortisoorllog om de controle over de Generale Maatschappij woor de Nederlanders met een sisser afliep. Dit zou een CGO-opdracht kunnen $z$ inn woor studenten.

Dat Maurice Lippens kort daarna door de koning tot de adalstand werd verheven houdt eigenlijk de hele verklaring in zich. Toch is dit moeilijk te begrijpen. Maar kort gezegd zit het probleem hierin: je moet thuis zijn in de netwerken die woor het besturen van de maatschappüj nodig zijn, will je succesvol de maatschappij besturen.

Het probleem is wellicht zo complex, dat een eenvoudige lezing wan teksten en discussie niet tot enig resultaat leiden. Meer diepgaande studie, uitgaande van de casusbeschrijving en gekoppeld aan de eis tot het opleveren wan een helder product, lijkt dan nodig.

Een paar woorden uitleg over de ABN-Fortisoorlog. Een deel van het tweede bendeonderzoek (Bende van Nijuel) betrof het verschijnsel wan de roze balletren, louche fuiven war politici, zakenwereld en magistraturur waren vertegenwoordigd. Het rapport citeert de niet-uitputting wan de onderzoeksmethoden naar dit bendenetwerk, de olympische snelheid in de afwikkeling wan het dossier van luxecallgirl Montaricourt, de snelle seponering van het analoge dossier Fortunato Israel, de verdwijning van het inmiddels berucht geworden 'plan de table', et cetera. Montaricourt en Istaël waren beiden opeenwolgend pr-managers van de firma Eurosystem, waarmee de Société Generale miljardencontracten met Saoedi-Arabie probeerde binnen te halen. Mevroww Israell was ook bevriend met wapenhandelaar Boas en stond ook op de loonlijst zilin wapenbedriff Asco. Ook multimiljardair Kashoggi was bekend cook wanwege het Lockheed-schandal warin Prins Bernhard in opspraak kwany); hii had zinn kantoor an het Terkamerenbos en had goede contacten met Vanden Boeynants. Dat de dossiers van de roze balletten snell verdwenen, is dan vrij evident. Fortunato Israel had contacten met rijkswachttopman Beaurir, met Boas en met Vanden Boeyenants. De zaken waren succesvol. Het consortium Eurosystem (onder leiding van de Generale Maatschappij) sloot een contract af van 36 miljard met de Saoedi's. De lobbyman van de Generale, pierre Gehot (die ook een rol speelde in het Agusta-Dassault verhaal), wordt de nummer en binnen Eurosystem. Na de moord op André Cools (n augustus rggr), legde hij als eerste 
het verband met het Agusta-contract. Binnen het Eurosystem-Hospitaliercontuact (28,5 miliand), werd acht miljard als smeergeld gebruikt en wor zogenaamde commissiegelden naar Zwitserse rekeningen gesluisd. Op verzoek van Eurosystem keurt de Minister yan Pinancien uitzonderlik snel goed dat deze commissielonen als bedrijfslast kunnen woulen ingeroepen (ter bewordering van de export). In leder geval was het voor de Bendecommissie bis mogelijk de Bende van Nijel op te sporen via de roze balletten. Bouhouche en Beijer stoniden terecht woor de moord op FN-ingenieur Mendez. Getugen uit de Bendeconmissle bis legden het verband tussen dit proces en de over-

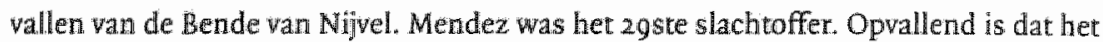
netwerk Fortunato en het milieu rond Eurosystem overlappend is met de mouvance Wihoul. It de club Mirano kwamen onder andere Bouhouche, Beijer (toen bij de BOB), Bultot, en Achiel en Patrick Haemers (wan de Bende Haemers). In het milien zaten ook de ondernemers De Paw en Blaton, die dankzll de steun wan Vanden Boyenants kantoorcomplexen als het World Trade Center neerpootten in Brussel.

De mouvance Nihoul blijkt, volgens professor De Ruyver, een bont allegaarje te zijn van politici, rechtshandhavers (politie, magistraten en advocaten) en zakenjongens die opduiken in tal wan dossiers zoals het Bendedossier, de zaak Mendez, de zaak Hatemers, de bende De Staerke, de zaak Corvillain, de roze balletten, de zaak Dutroux, et cetera. Een netwerk van macht, politiek, wapenhandel en wennootschappen Janssens, 1998). Een hoger bod wanwege ABN was tevergeef. Of de Euro daar hets aan verandert valt zeer te betwijfelen.

Mijtns inziens kan een verdere ontwikkeling van het universitair onderwijs in de richting van het CGO dit soort complexe relaties voor studenten duidelijk maken. De juridische realiteit is inmers een realiteit en een interpretatie daarvan. Productgericht werken bevordert diepgaande exploratie van de casus en efficient werken aan de op lossing.

Dames en heren, als u na afloop wan deze rede het volgende niet vergeet ben ik een tevreden mian:

I in het juridisch onderwijs zal de toepassing van instructietechnologie nog sterk toemerner:

2 constructiegericht onderwijs binnen de juridische wetenschap is een na te streven doe:

3 innovatieve strategieen woor probleemoplossen en innowatie van instructie moeten onderzoclut, onwikkeld en geimplenenteerd worden. De juridische wetenschap zal daarin wellichteen domeinspecifieke anpak en profilering vereisen.

Op basis van eerdere ervaring zou ilk nog tot de volgende stellingen willen komen:

4 complexe softwaresystemen ontwikkelen heeft weinig slaagkamsen enfof geen genenieke toepassingswaarde; 
5 onderwijsresearch is per definitie toepassingsgericht (op in casu juridisch onderwiijs);

6 innovaties vereisen diverse implementatiestrategieen;

7 Beleid \& Research zijn productgericht en gekoppeld aan timemanagement;

8 het Maastrichtse PGO kan zich het beste ontwikkelen in de richting van het geschetste CGO.

\section{Dankwoord}

Dank aan het College van Bestuur en het bestuur van de faculteit woor het wertrouwen in mijn komende activiteiten.

Dark aan u allen om aanwezig te zijn.

Ik heb gezegd. 


\section{Referentites}

Birenbaum, M., \&ochy, F. (Eds.) (2996). Altematives in Assessment of Achtevement. Learning Processes and Prior Knowldge. Boston: Kilwwer Acadenic.

Bransford, J.D. (r979). Human cognition. Belmont, California. Wadsworth.

Brown, J.S., Collins, A, \& Dugid, P. (rg8g). Situated cognition and the culture of learning. Educational Researher, 32 .

De Corte, F. (rogo). Towards powerful leaming enwitonments for the acquisition of problem solving skills. European Joumal of Psychology of Edwcation, $5,1,5 \%$.

Dochy, F, \& Moerkerke, G. (1997). The present, the past and the future of achievement resting and performance assessment. Intemational Joumal of Educational Research, 27 , $5: 4.15-432$

Dochy, R., \& Van Luyk, S.J. (1987) Handboek Vaardighedsondewijs. Lisse: Swets \& Zeitlinger:

Dochy, F, \& de Rike, T.R. (1995). Assessment Centers: nieuwe topassingen in opleiding, onderwijs en Human Resource Marlagment.. Utrecht: Lemma.

Dochy, F., Segers, M. \& Moerkerke, $\mathrm{G}_{\text {( }}(1996$ ). The importance of prior knowledge and assessment for increasing efficiency of the leaming processes, especially in problem-based powarful learning enviromments. International Joumal of Agricultural Education, 3, 3, 14I-1.67"

Dochy, F., \&. Wijnen, W. (I987). Vernieuwd onderwijs aan de Rjjksuniversiteit Limburg: revolutionair of up-to-date? De Maastrichtse universiteit en het traditioneel universitair systeem in onderaijskundig perspectief. Persoon \& Gemenschap, 36, 7, 258-27r.

Dochy, EJ.R.C., Wijnen, W.H.F.W., \& Segers, M.S.R,(1987). Ower de relatieve betekenis, functies en keuze wan performance indicatoren woor kwaliteitsbewaking van het 'onderwijs'. Universiteit en Hogeschool, $34,2,73-83$.

Falchikov, N. \& Boud, D. (1989). Student Self-Assessment in Higher Education: A Meta-Analysis. Review of Educational Research, 59 (4), 395-430.

Feletti, G. (1992). Inguiry based and problem based leaming: How similar are these approaches? Paper presented at the PBL Education and Training Conference, Sydney, december xg92.

Glaser, R, \& Corte, E. (1992). Preface to the assessment of prior knowledge as a deteminant for future Learning. In Dochy, F. (1992). Assessment of prior knowledge as a deteminart for future leaming $(1-2)$. Utrecht/London: Lemna B.V.llessica Kingsley Dublishers (http:/ericae net/books/dochy/).

Janssens, S. (1998). De natmen uit de doofpot. Berchem: Epo.

Le Brun, M. \& fohnstone, R. (1994). The quiat (r)evolution. Improving student learning in law. Sycney: The Law Book Company Limited.

Martens, R. (1998). The use and ffects of embedded support devices in independent leaming. Utrecht: Lemma.

Martens, $\mathbb{R}$ \& Dochy, F (1997). Assessment and feedback as student support devices. Studies in Educational Eurluation, $23,257-275$ " 
Moerkerke, G. (1996). Assessment for flexible Leomitu. Utrecht: Lema.

Nhou, N. (1998). Geruthten en feiten: dutobiografie. Dark \& Light Publication.

Ogden, G.L. (rg84). The problem method in legal education. Journal of Legal Bduration, $34,654-655$.

Rapport Benderommissie bis, Belgische Kamer wan Volksvertegenwoordigers, zitting 1997 1998,34 oktober 1997 , document nr. 573/7-95-96, Parlementair onderzoek nar noodzakelijke aanpassingen van de organisatie en de werking van het politie- en justitiewezen op basis van de moeillikheden die gerezen zijn bij het onderzoek naar de 'Bende van Nivel'.

Rapport Dutrowx (2), Belgische Kamer van Volkswertegenwoordigers, 16 februari 1998 , document nr. $713 / 8-96 / 97$. Parlementair onderzolk naar de wijze waarop het ondar zoek door de polltie en gerecht werd gevoend in de zaak 'Dutrowx-Nihoul en consorten, aanullend verslag".

Rapport eerste bendecommissie, Belgische Kamer van Volksvertegenwoordigers, 30 april rggo, document nr. 59/80-1988:

Rapport wapentrafieken, Belgische Kamer van Volkswertegenwoordigers, zitting ro88I989, document nr. $137 / 6$-Ig88, 28 februari 1989 , Parlementair onderzoek naar de Belgische leveringen van wapens en munitie aan landen die in een gewapend conflict werwikkeld zijn of waartegen een wapenembargo geldt.

Ronteltap, F. \& Eurelings, A. (r998). Eindrapport Polarts. Maastricht: Universiteit Maastricht.

Schank, R.C., Abelson, R.P. (r977). Script, plans, goals and understanding: An inguiry into human knowledge struttures. Hillsdale, N.J.: Lawrence Eribaum.

Segers, M., Tempelaar, D., Keizer, P., Schijns, J., Vaessen, B, \& Van Mourilk, A. (1992). De OverAll Toets: een tweede experiment met eent nieuwe toetsuorm. [IThe OverAll test: $A$ second experiment]. Maastricht: University of Maastricht.

Segers, M.S.R. (rgg6). Assessment in a Problem-Based Economics Curriculum. In: M. Birenbaum, \& F. Dochy (eds.). Altematives in assessment of achievements, leaming processes and prior knowledge. Boston/Dordrecht/London: Kluwer Academic Publishers.

Segers, M.S.R. (I997). An Alternative for assessing problem-solving skills: the OverAll test. Studies in Educational Evaluation, $23,4,373-398$.

Sluijsmans, D., \& Dochy, F (1998), Alternatieve toetsmethoden in studentgericht onderwijs. Thidschtift woor Hoger Onderwijs, 4, 298-314.

Timmermans, G. (I9gi). In Brussel mag alles: geld, mach en betow. EPO.

Tribe, D.M. \& Tribe, A.). (1987). Lawteach: an interactive method for effective large group teaching. Studies in Higher Education, 12, 299-312.

Valcike, M., Dochy, E, et al. (1995). Alternative Assessment Procedures: Recent Trends and Experiences from Practice. The Law Teacher. The International Journal of Ligal Education, $20,3.322-335$.

Werwaest, Ch. (1998). De justitiggids. Het labyrint van het Belgisch gerecht met de niewwe hervor mingent wan het Octopus-akkoond inzake poltite en justitie. Roeselare: Globe. 


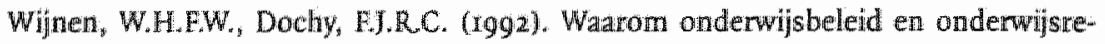
search strijdig kunnen zijn: voorbeelden, verklaringen en oplossingen. Tijdschrift voor Hoger Onderwijs, 10, 4, 252-265. 


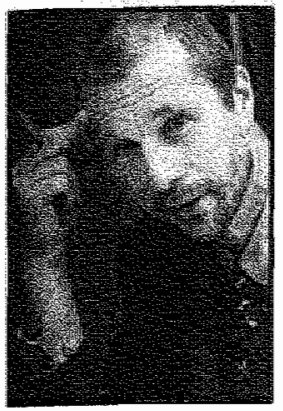

Prof. dr. F. Dochy 